\title{
MRI of Diffusely Infiltrating Intracranial Astrocytomas: Association between the Volume of Peritumoural Edema and the degree of Contrast Enhancement
}

\author{
ROBERT AHMED KHAN ${ }^{1}$, S I M KHAIRUN NABI KHAN², \\ MAHFUZUR RAHMAN ${ }^{3}$, MAFZAL HOSSAIN $^{4}$
}

\begin{abstract}
:
Background: The development of peritumoural edema and contrast enhancement of brain tumour is both thought to be due to breakdown of blood-brain barrier. However, the exact mechanisms by which these phenomena occur are not completely understood. Our purpose was to find association between the volume of peritumoural edema and the degree of contrast enhancement in MRI of diffusely infiltrating astrocytomas. Method: A total of 42 patients with intracranial astrocytomas diagnosed by MRI findings who underwent surgery with histopathology showing diffusely infiltrating astrocytomas were selected from the study population. The volume of peritumoural edema was measured and visual assessment of the degree of contrast enhancement was scored. Result: A highly significant association was found $(p<0.001)$ between the volume of peritumoural edema and the degree of contrast enhancement. Conclusion: These results can be viewed as indirect, radiological evidence that edema production is quantitatively related to the degree of breakdown of the $B B B$ as determined by the gadolinium enhancement.
\end{abstract}

KEY WORDS: Astrocytoma, Peritumoural edema, Degree of contrast enhancement

Abriviation: BBB (Blood brain barrier), CT (Computary tomography), MRI (Megneting resonance imaging).

Introduction:

Brain edema associated with brain tumour is one of the most important factor contributing to the morbidity and mortality associated with brain tumour. The major mechanism for edema formation within and around brain tumour is abnormal permeability of newly created microvessels in the growing tumour. It was found that endothelial proliferation is common in malignant gliomas and that new tumour vessels are derived from previously existing vessels. However, these newly formed vessels are often defective. These defective vessels form an ineffective barrier and allow leakage of plasma exudates into the surrounding brain ${ }^{1}$. It is thought that enhancement of brain tumour by contrast media in CT and MRI is due to open interendothelial junctions, fenestrae, gap junctions and increased pinocytic vesicles in the capillaries of these tumours ${ }^{2}$. However, it is not known whether the putative defect, which governs the development of edema, is the same as one, which causes contrast enhancement. It is also not known whether these two factors are related to each other or how they are related to the degree of damage to the BBB. The present study is aimed finding association between the volume of peritumoural edema and the degree of contrast enhancement in MRI of diffusely infiltrating astrocytomas.

Material and methods:

This study was carried out at the Department of Neurosurgery, Bangabandhu Sheikh Mujib Medical

1. Medical Officer, Department of Neurosurgery, Bangabandhu Sheikh Mujib Medical University,Dhaka.

2. Assistant Professor, Department of Neurosurgery, Bangabandhu Sheikh Mujib Medical University, Dhaka

3. Resident, Department of Neurosurgery, Bangabandhu Sheikh Mujib Medical University, Dhaka.

4. Professor and Chairman, Department of Neurosurgery, Bangabandhu Sheikh Mujib Medical University, Dhaka. 
University, Dhaka, during the period from July 2006 to April 2008. All admitted patients with intracranial astrocytomas who underwent surgery were considered as a study population. A total of 42 patients with intracranial astrocytomas diagnosed by MRI findings who underwent surgery with histopathology showing diffusely infiltrating astrocytomas were selected from the study population.

The volume of tumour and edema was measured by modified ellipsoid formula simply by $p / 6{ }^{\prime} A B C$ which practically amounts to $1 / 2^{\prime} A B C$ where $A=$ Largest anterior- posterior length in centimeter, $\mathrm{B}=$ Largest width in centimeter, $\mathrm{C}=$ Largest vertical length in centimeter. To measure volume of edema initially both tumour and edema volume was calculated as a unit, then the tumour volume was subtracted from the total (Fig. 1).

Visual evaluation of the degree of contrast enhancement was scored on 0-2 scale, with $0=$ no enhancement (Fig. 2), 1 = equivocal enhancement (Fig. 3) and 2 = definite enhancement ${ }^{3}$ (Fig. 4).

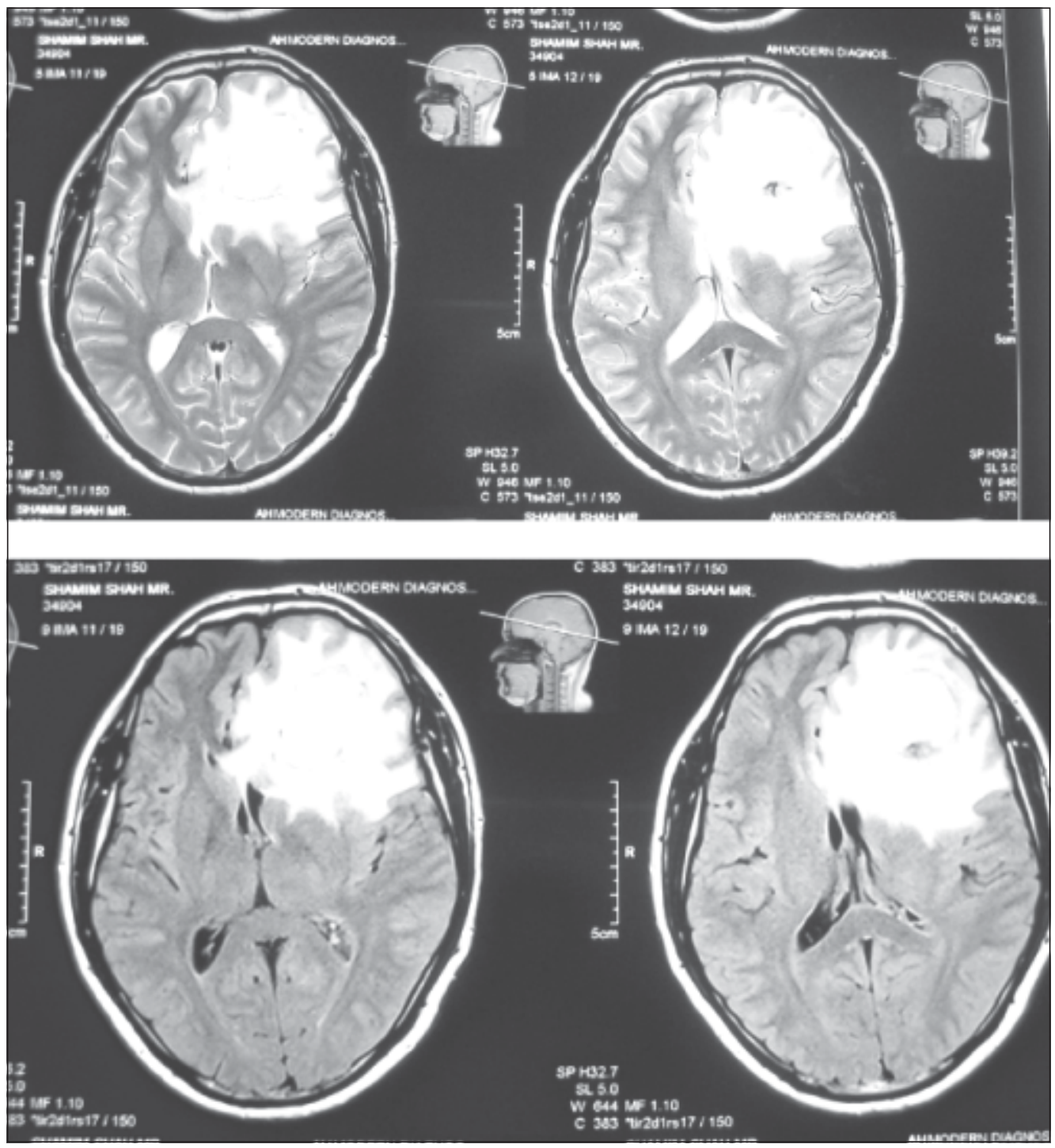

Fig.-1: MRI of GBM, T2 weighted image\& Flair showing peritumoural edema. 


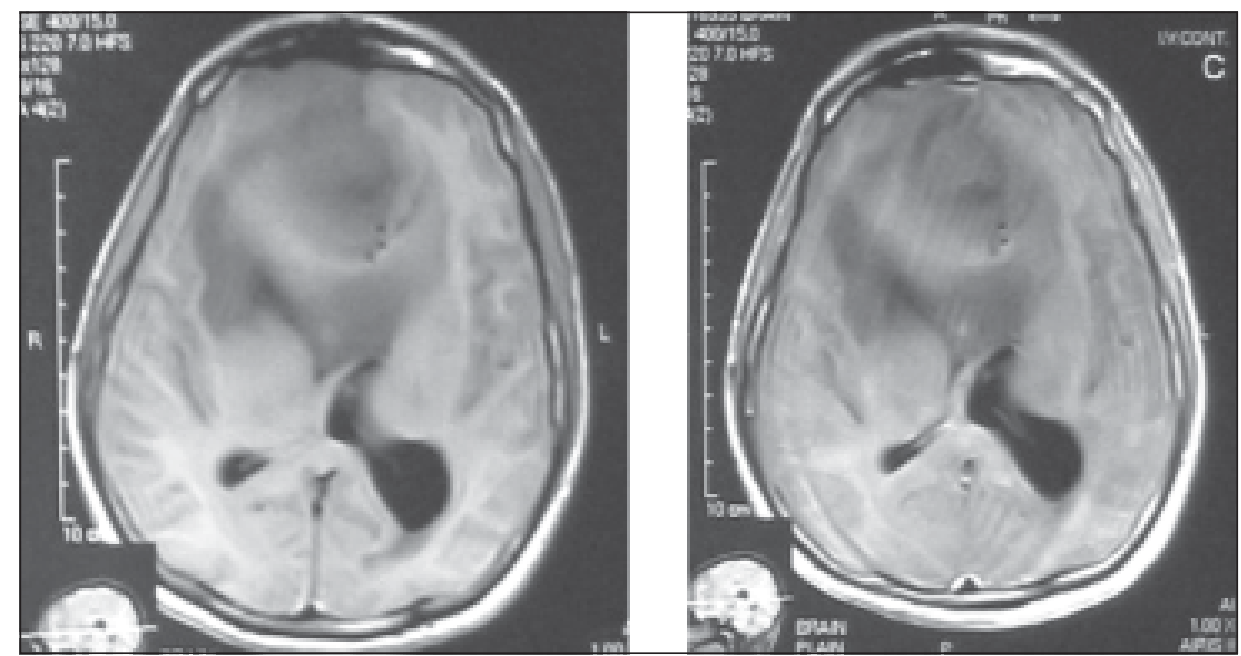

Fig.-2: MRI of low grade glioma, T1 weighted image Pre \& Post-contrast. Degree of contrast enhancement: None.

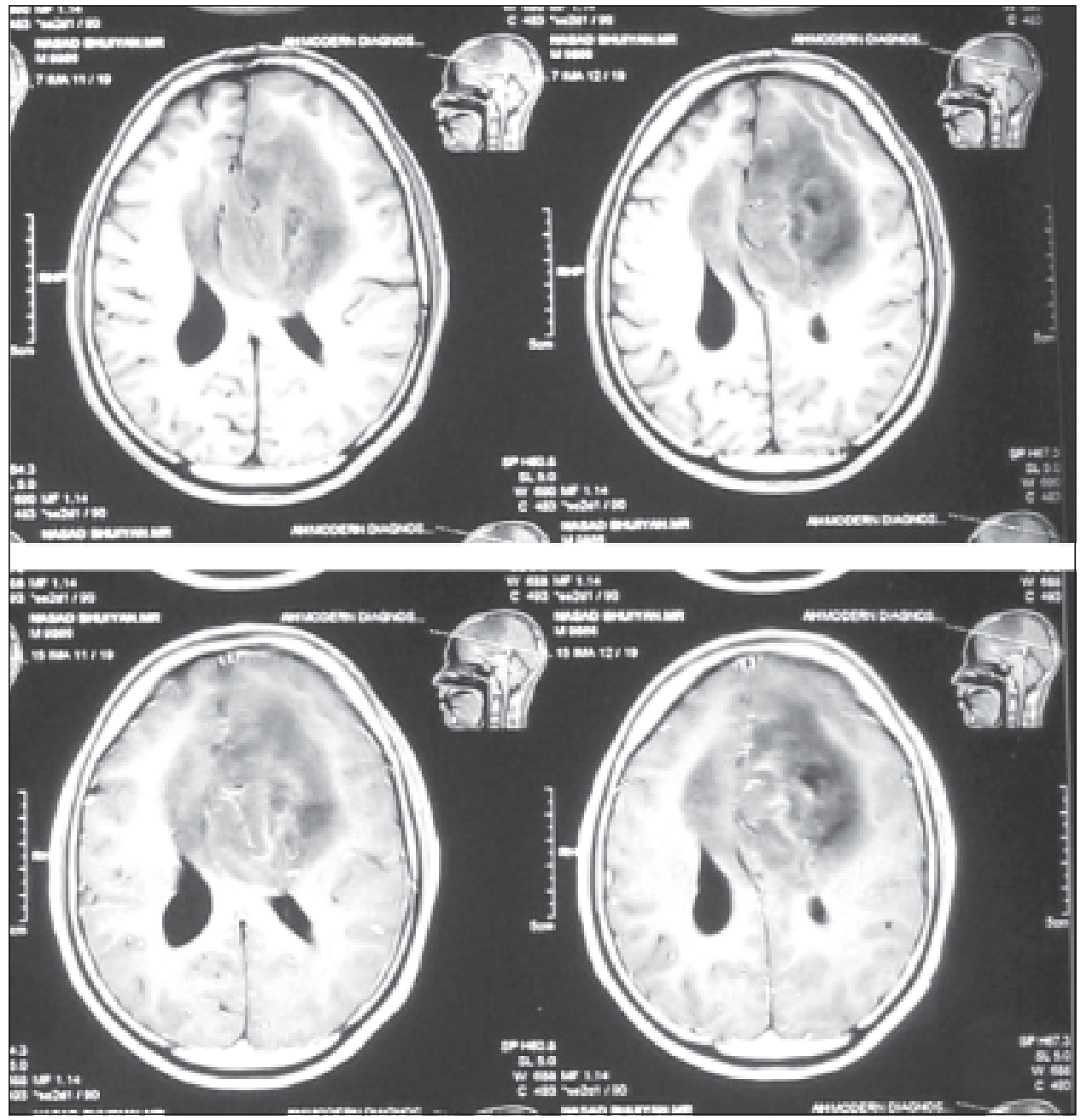

Fig.-3: MRI of Low grade glioma, T1 weighted image Pre \& Post-contrast. Degree of contrat enhancement: Equivocal. 

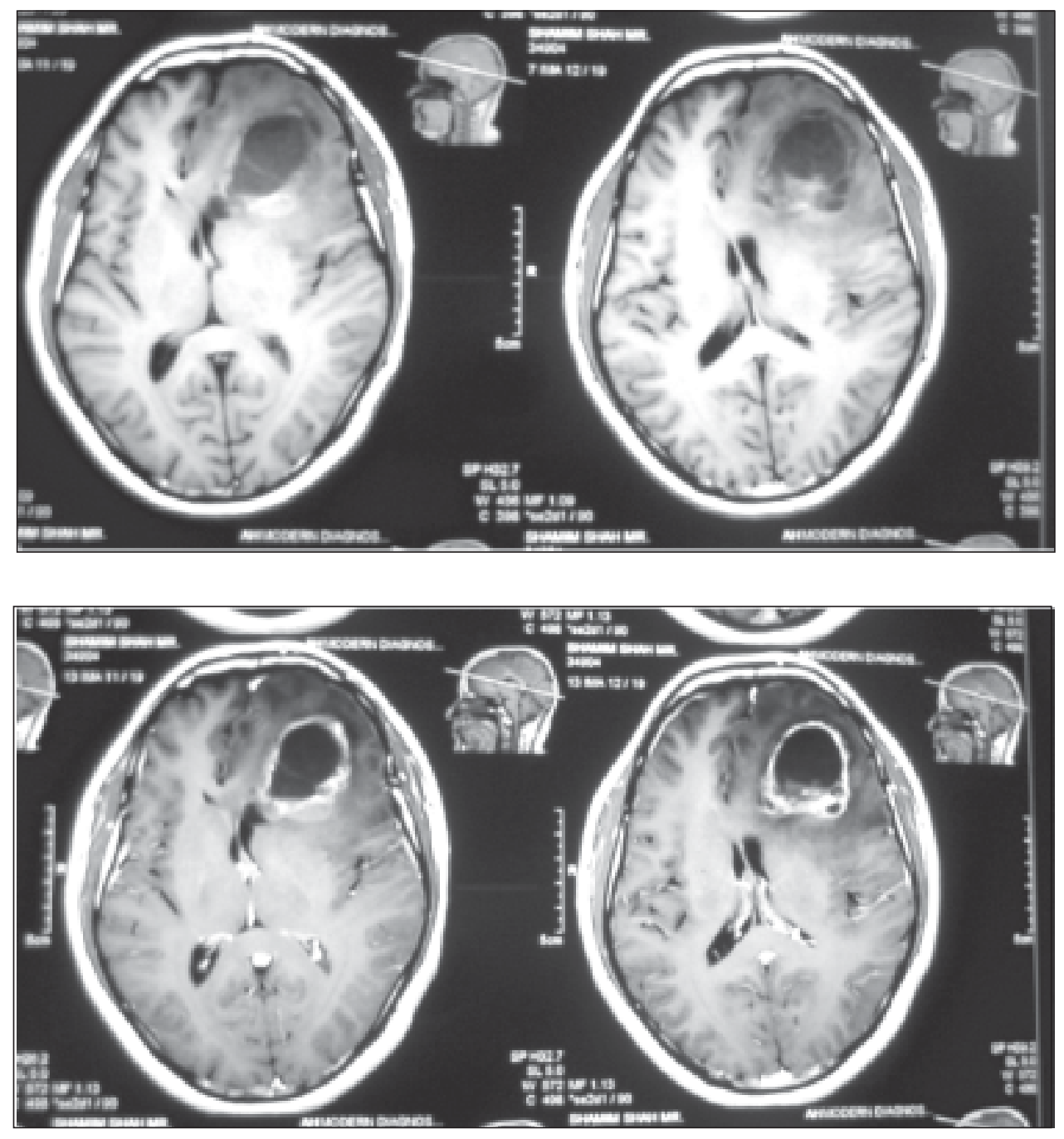

Fig.-4: MRI of GBM, T1 weighted image Pre \& Post-contrast. Degree of contrast enhancement: definite.

\section{Results:}

A total of 42 cases of diffusely infiltrating astrocytomas diagnosed by MRI and cofirmed by histopathological report were taken as study sample. The age distribution of 42 patients ranged from $8-60$ years. The mean \pm SD age was $36.6 \pm$ 14.28. The peak age incidence was $31-40$ age group (Table I). A male preponderance was observed among the admitted cases with male to female ratio was $2.5: 1$. In this study, out of 42 patients of intracranial astrocytomas, regarding location of the tumour, maximum 29(69\%) patients had hemispheric lesions. 6(14.3\%) patients had cerebellar lesion, 6(14.3\%) patients had diencephalic lesion and 1(2.4\%) patient had brainstem lesion (Table II). Regarding the volume of tumour maximum patients 21 (50\%) had tumour volume of $<25 \mathrm{cc}$. The range of tumour volume was $2-224 \mathrm{cc}$. The range of peritumoural edema volume was $0-137 \mathrm{cc}$. Maximum 21 patients had edema volume $>50 \mathrm{cc}$ (Table III). Most of the astrocytoma's showed definite degree of contrast enhancement i.e. 31 (73.8\%) with $6(14.6 \%)$ having no contrast enhancement and 5 (11.9\%) having equivocal degree of contrast enhancement (Table IV). Histopathologically $26.2 \%$ was grade II astrocytoma, $21.4 \%$ was grade III astrocytoma and $52.4 \%$ were grade IV astrocytoma (Table V).

Association between the volume of peritumoural edema and the degree of contrast enhancement 
was found significant $(p<0.001)$ in $95 \%$ confidence limit (Table VI). More the volume of peritumoural edema, more was the degree of contrast enhancement. The study demonstrated significant association $(p<0.001)$ between volume of peritumoural edema and histological subtype in patients with diffusely infiltrating astrocytomas (Table VII). The present study also showed significant correlation $(p<0.001)$ between the degree of contrast enhancement and histopathological subtype of tumour (Table VIII).

Table-I

Age distribution of patients with Astrocytomas

\begin{tabular}{lcc}
\hline Age group in year & Frequency & Percent \\
\hline$<10$ & 2 & 4.8 \\
$11-20$ & 4 & 9.5 \\
$21-30$ & 9 & 21.4 \\
$31-40$ & 11 & 26.2 \\
$41-50$ & 10 & 23.8 \\
$>50$ & G & 14.3 \\
\hline Total & 42 & 100 \\
\hline
\end{tabular}

Table-II

Location of tumour in patients with diffusely infiltrating astrocytomas

\begin{tabular}{lcc}
\hline Location of tumour & Frequency & Percentage \\
\hline Hemispheric & 29 & 69 \\
Cerebellar & 6 & 14.3 \\
Diencephalic & 6 & 14.3 \\
Bramstem & 1 & 2.4 \\
\hline Total & 42 & 100 \\
\hline
\end{tabular}

Table-III

Volume of peritumoural edema in patients with astrocytoma

\begin{tabular}{lcc}
\hline Edema volume (cc) & Frequency & Percentage \\
\hline 25 & 13 & 31 \\
$25-50$ & 8 & 19 \\
50 & 21 & 50 \\
\hline Total & 42 & 100 \\
\hline
\end{tabular}

Table-IV

Degree of contrast enhancement in patients with astrocytoma

\begin{tabular}{lcc}
\hline $\begin{array}{l}\text { Degree of contrast } \\
\text { enhancement }\end{array}$ & Frequency & Percent \\
\hline None & 6 & 14.6 \\
Equivocal & 5 & 11.9 \\
Definite & 31 & 73.8 \\
\hline Total & 42 & 100 \\
\hline
\end{tabular}

Table-V

Histopathological subtypes in patients with astrocytoma

\begin{tabular}{lcc}
\hline Histopathology & Frequency & Percentage \\
\hline Low grade astrocytoma & 11 & 26.2 \\
Anaplastic astrocytoma & 9 & 21.4 \\
Glioblastoma multiformae & 22 & 52.4 \\
\hline Total & 42 & 100 \\
\hline
\end{tabular}

Table-VI

Association between the volume of peritumoural edema and the degree of contrast enhancement

\begin{tabular}{|c|c|c|c|c|c|c|}
\hline \multirow{2}{*}{$\begin{array}{l}\text { Degree of } \\
\text { contrast } \\
\text { enhancement }\end{array}$} & \multicolumn{4}{|c|}{ Volume of peritumoural edema (cc) } & \multirow{2}{*}{\multicolumn{2}{|c|}{$\begin{array}{c}\chi^{2} \\
\text { value }\end{array}$}} \\
\hline & $<25$ & $25-50$ & $>50$ & Total & & \\
\hline None & 6 & 0 & 0 & 6 & 26.46 & $<0.001$ \\
\hline Equivocal & 4 & 1 & 0 & 5 & & \\
\hline Definite & 3 & 7 & 21 & 31 & & \\
\hline Total & 13 & 8 & 21 & 42 & & \\
\hline
\end{tabular}

Table-VII

Association between the volume of peritumoural edema and the hitopathological subtype

\section{of tumour}

\begin{tabular}{lcccccc}
\hline $\begin{array}{l}\text { Histo- } \\
\text { pathological }\end{array}$ & \multicolumn{7}{c}{ Volume of peritumoural edema (cc) } & $\begin{array}{c}\chi^{2} \\
\text { value }\end{array}$ & $\begin{array}{c}\mathrm{p} \\
\text { value }\end{array}$ \\
\cline { 2 - 5 } & $<25$ & $25-50$ & $>50$ & Total & & \\
\hline $\begin{array}{l}\text { Luw grade } \\
\text { astocytoma }\end{array}$ & 9 & 2 & 0 & 11 & 22.95 & $<0.001$ \\
$\begin{array}{l}\text { Anaplastic } \\
\text { astrocytoma }\end{array}$ & 2 & 3 & 4 & 9 & \\
$\begin{array}{l}\text { Glioblastoma } \\
\text { multiforme }\end{array}$ & 2 & 3 & 17 & 22 & \\
\hline Total & 13 & 8 & 21 & 42 & & \\
\hline
\end{tabular}


Table-VIII

Association between the degree of contrast enhancement and the hitopathological subtype of astrocytomas

\begin{tabular}{lcccccc}
\hline Histo- & \multicolumn{2}{l}{ Degree of contrast enhancement } & $\chi^{2}$ & $\mathrm{p}$ \\
\cline { 2 - 6 } $\begin{array}{l}\text { pathological } \\
\text { subtype }\end{array}$ & None Equivocal & Definite & Total & value & value \\
\hline $\begin{array}{l}\text { Low grade } \\
\text { astocytoma }\end{array}$ & 5 & 5 & 1 & 11 & 33.34 & $<0.001$ \\
$\begin{array}{l}\text { Anaplastic } \\
\text { astrocytoma }\end{array}$ & 1 & 0 & 8 & 9 & \\
$\begin{array}{l}\text { Glioblastoma } \\
\text { multiforme }\end{array}$ & 0 & 0 & 22 & 22 & \\
\hline Total & 6 & 5 & 31 & 42 & \\
\hline
\end{tabular}

\section{Discussion:}

The question of peritumoural edema remains pivotal for the clinical management of the patients with astrocytomas. Understanding brain edema is crucial to the effective treatment of tumours. The present study was conducted at the department of Neurosurgery, BSMMU, Dhaka during the period of July 2006 to April 2008 to find the association between the volume of peritumoural edema and the degree of contrast enhancement as seen in MRI of diffusely infiltrating astrocytomas. The final study subjects were 42 patients with diffusely infiltrating astrocytomas. The age ranged from 8 years to 60 years. Mean age was 36.6 years. The highest incidence was in between 31- 40 years. Age incidence in diffusely infiltrating astrocytomas is an important variable, which is observed to vary from study to study. In present study, no particular age was found susceptible to develop astrocytoma, although more than one third (38\%) of the study cases were the age of 40 years or above. The mean age was found to be 36.6 years which is almost consistent with the findings of other series ${ }^{4,5}$. Variation of astrocytomas with respect to sex is not also uncommon. Astrocytomas are more common in males $(M: F=3: 1)^{6}$. In our study we found a male predominance at the ratio of 2.5:1 bearing consistency with findings of other investigators ${ }^{4}$.

In the present study regarding the location of tumour, hemispheric lesions were commonest (69\%) followed by cerebellar and diencephalic lesions
(14.3\%). The brainstem variety was least common (2.4\%). In adult cases hemispheric astrocytomas were common while cerebellar lesions were more common in children ${ }^{6}$. This was not observed in the present study probably due to the fact that pilocytic astrocytoma,one of the more common pediatric brain tumour was not included in the study.

In this study, regarding peritumoural edema volume, maximum 21 patients had edema volume $>50 \mathrm{cc}$. The Mean \pm SE of peritumoural edema volume was $56.36 \pm 6.76 \mathrm{cc}$. The range of peritumoural edema volume was $0-137 \mathrm{cc}$.

In the present study regarding degree of contrast enhancement, 6 (14.6\%) patients showed no enhancement, 5 (11.9\%) patients showed equivocal enhancement and 31 (73.8\%) patients showed definite enhancement after administration of contrast agent. Association between the volume of peritumoural edema and the degree of contrast enhancement was found significant $(p<0.001)$ in $95 \%$ confidence limit. More the volume of peritumoural edema more was the degree of contrast enhancement. The findings offer indirect radiological evidence that the defect in the BBB which causes edema is etiologically related to the defect in BBB responsible for contrast enhancement ${ }^{7}$. Significant correlation can be found $(p=0.0006)$ between the volume of peritumoural edema and the degree of contrast enhancement in gliomas ${ }^{8}$.

In our study regarding histopathological diagnosis, $26.2 \%$ was grade II astrocytoma, $21.4 \%$ was grade III astrocytoma and $52.4 \%$ were grade IV astrocytoma. In diffuse fibrillary astrocytomas there is direct correlation between peritumoural edema with tumour grade $(p<0.01)^{9}$. Our study also demonstrated significant association $(p<0.001)$ between volume of peritumoural edema and histological subtype in patients with diffusely infiltrating astrocytomas.

The present study also showed significant correlation between the degree of contrast enhancement and histopathological subtype of tumour $(p<0.001)$. This was also found in another study $^{10}$. It was also found that there is direct relationship between contrast enhancement and 
neovascularity present in high grade tumours ${ }^{11}$. However, in low-grade astrocytomas with little or no alteration of BBB, contrast agent did not enter the extravascular space and no significant contrast enhancement was observed ${ }^{12}$.

\section{Conclusion:}

In our study we have found that there is significant association between the volume of peritumoural edema and the degree of contrast enhancement in MRI of diffusely infiltrating intracranial astrocytomas. Thus the finding of the study is in concordance with our hypothesis. The finding for astrocytomas offers indirect radiological evidence that the defect in BBB which causes edema is etiologically related to the defect in the BBB responsible for contrast enhancement. We have also found significant association between the degree of contrast enhancement and the volume of peritumoural edema found in MRI with histopathological subtypes of diffusely infiltrating intracranial astrocytomas. The findings suggest that astrocytoma subtypes have a characteristic profile of MRI.

\section{References:}

1. Bruner, MJ, Tien, RD \& Thorstad, WL. Structural changes produced by intracranial tumours and by various forms of antineoplastic therapy, in Russell and Rubinstein's pathology of tumours of the nervous system, Bigner, DD, McLendon, RE \& Bruner MJ (eds.), $6^{\text {th }}$ edn, Arnold, New York 1998; 2: pp. 451-92.

2. Sage, MR \& Wilson, AJ. 'The blood-brain barrier: an important concept in neuroimaging', American Journal of Neuroradiology 1994; 15: pp. 601-2.

3. Brant-Zawadzki, M, Berry, I, Osaki, L, Brasch, R, Murovic, J \& Norman, D. 'Gd-DTPA in clinical MR of the brain: 1. Intraaxial Lesions', American Journal of Radiology 1986; 147: pp. 1223-30.
4. Guillamo, JS, Monjour, A, Taillandier, L, Varlet, P, Hai-Meder, C, Defer, GL. 'Brainstem glioma in adults, prognostic factor and classification', Brain 2001; 124: 2528- 39.

5. Dastur, HM \& Lalita, VS, Intracranial Tumour Pathology, in Text book of Neurosurgery, Ramamurthi,B \& Tandon, PN (eds.), 1st edn, National Book Trust, India 1980; 2: 733-86.

6. Ramamurthi, B, Gliomas, in Textbook of Neurosurgery, Ramamurthi, B \& Tandon, PN (eds.), 1st edn, National Book Trust, India 1980; 2: 848-64.

7. Pronin, I, Holodny, AI \& Petraikin, AV. 'MRI of high-grade glial tumours: correlation between the degree of contrast enhancement and the volume of surrounding edema', Neuroradilogy 1997; 39: 348-50.

8. Holodny, AI, Nusbaum, AO, Festa, S, Pronin, I, Lee, HJ \& Kalnin, AJ. 'Correlation between the degree of contrast enhancement and the volume of peritumoural edema in meningiomas and malignant gliomas' Neuroradiology 1999; 41: 820-5.

9. Tervonen, O, Forbes, G, Scheithaurer, BW \& Dietz, MJ. 'Diffuse fibrillary astrocytomas: correlation of MRI features with histopathologic parameters and tumour grade', Neuroradiology 1992; 34: 173-8.

10. Reimann B, Papke K, Hoess N. 'Noninvasive grading of untreated gliomas: A comparative study of MR imaging and 3-(iodine 123)-L-士Methyltyrosine SPECT', Radiology 2002; 225: 567-74.

11. Watanabe, M, Tanaka, R \& Takeda, N, 'Magnetic resonance imaging and histopahology of cerebral gliomas', Neuroradiology, 1992; 34: 463-9.

12. Asari, S, Makabe, T, Katayama, S, Itoh, T, Tsuchida, S \& Ohmoto, T. 'Assessment of the pathological grade of astrocytic gliomas using an MRI score', Neuroradiology 1994; 36: 308-10. 